\title{
Carotid Artery Atherosclerosis: A Review on Heritability and Genetics
}

\author{
Bianka Forgo, ${ }^{1}$ Emanuela Medda, ${ }^{2}$ Anita Hernyes, ${ }^{1}$ Laszlo Szalontai, ${ }^{1}$ David Laszlo Tarnoki, ${ }^{1}$ \\ and Adam Domonkos Tarnoki ${ }^{1}$ \\ ${ }^{1}$ Department of Radiology, Semmelweis University, Budapest, Hungary \\ ${ }^{2}$ Centre for Behavioural Sciences and Mental Health, Istituto Superiore di Sanità, Rome, Italy
}

\begin{abstract}
Carotid atherosclerosis (CAS) is associated with increased cardiovascular risk, and therefore, assessing the genetic versus environmental background of CAS traits is of key importance. Carotid intima-mediathickness and plaque characteristics seem to be moderately heritable, with remarkable differences in both heritability and presence or severity of these traits among ethnicities. Although the considerable role of additive genetic effects is obvious, based on the results so far, there is an important emphasis on non-shared environmental factors as well. We aimed to collect and summarize the papers that investigate twin and family studies assessing the phenotypic variance attributable to genetic associations with CAS. Genes in relation to CAS markers were overviewed with a focus on genetic association studies and genome-wide association studies. Although the role of certain genes is confirmed by studies conducted on large populations and meta-analyses, many of them show conflicting results. A great focus should be on future studies elucidating the exact pathomechanism of these genes in CAS in order to imply them as novel therapeutic targets.
\end{abstract}

Keywords: carotid atherosclerosis, heritability, genetics, genome-wide association study, cardiovascular risk

Atherosclerosis is a chronic disease of the arteries characterized by inflammation and plaque building in the arterial wall, eventually leading to stenosis of the vessel. Carotid atherosclerosis (CAS), which is the manifestation of atherosclerotic disease in the cervical arteries, is associated with increased risk for cardiovascular diseases (CVDs) (Chambless et al., 1997; Ebrahim et al., 1999; Lorenz et al., 2007). CVDs are responsible for $31 \%$ of deaths globally, being the leading cause of death worldwide, and of all CVD deaths, $80 \%$ are attributable to stroke and myocardial infarction (World Health Organization, 2017). Carotid intima-media-thickness (CIMT), plaque, and stenosis are measurable traits indicating CAS. Several studies have confirmed that increased CIMT is the distance between the lumen-intima and the media-adventitia interfaces as assessed by ultrasound and is a predictor of coronary heart disease and cerebrovascular events, such as stroke (Bots et al., 1997; Chambless et al., 1997, 2000; Howard et al., 1993; Lorenz et al., 2007; Polak et al., 2011; Salonen \& Salonen, 1991; van der Meer et al., 2004). Furthermore, CIMT is a marker of subclinical atherosclerosis (Naqvi et al., 2010), and prospective studies have shown that the subclinical stage of atherosclerosis is associated with clinical coronary artery disease (Kuller et al., 1995).
The tools for non-invasive assessment of CAS include B-mode ultrasound and time-of-flight magnetic resonance angiography, or contrast-enhanced magnetic resonance angiography. Ultrasound is a well-established and widely used method to detect carotid artery pathologies since it is highly repeatable, reproducible, and sensitive (Heiss et al., 1991; Stein et al., 2008). According to a meta-analysis on CIMT reproducibility, intra- and interobserver variability varied between $62 \%$ and $97 \%$ and between $58 \%$ and $100 \%$, respectively (Kanters et al., 1997). However, the measurement error increased if maximal instead of mean CIMT was registered and if internal CIMT instead of common CIMT was measured (Kanters et al., 1997). MRI may provide additional information on plaque characteristics (Kerwin et al., 2013). The invasive imaging methods of the CAS include contrast-enhanced computer tomography, magnetic

RECEIVEd 6 March 2018; ACCEPTEd 21 May 2018. First published online 6 July 2018.

ADDRESS FOR CORRESPONDENCE: Adam Domonkos Tarnoki $\mathrm{MD}, \mathrm{PhD}$, Semmelweis University Department of Radiology, Üllői Street 78/A, Budapest 1082, Hungary. E-mail: tarnoki2@ gmail.com 
resonance, and catheter (digital subtraction) angiography. Plaque size relative to the resolution of magnetic resonance imaging influences the reliability of magnetic resonance angiography, which ranges between 0.38 and 0.89 for wall and cap thickness and between 0.66 and 0.94 for vessel area (Wasserman et al., 2010). Reliability or measurement error is an important factor to consider since it is a part of unique environmental variance (E), an important driver of the magnitude of heritability estimates.

Twin and family studies along with candidate gene analyses and genome-wide association studies (GWAS) have a crucial role to explore detailed genetic and environmental effects on these important markers of cardiovascular disease. Investigating underlying factors affecting the condition of carotid arteries is essential for future individualized treatment and prevention aspects. The present review aims to overview the studies that investigate the background of phenotypic variances of carotid artery atherosclerosis markers and possible responsible genes, with the focus on recent results.

\section{Methods}

To find the most appropriate articles for our topic, searches in PUBMED and the Web of Science database were conducted. First, we searched using the following keywords in the title or abstract: carotid, atherosclerosis, family study, twin study, heritability, heredity, parent offspring, parent child, and atherosclerosis. Second, we performed a separate search in order to review genes associated with carotid artery atherosclerosis with the key words candidate gene, genome-wide association, and carotid. The first search resulted in 152 articles, of which 41 were considered as relevant to our topic, and the second search resulted in 125 articles, of which 22 were included. Articles exclusively in English were considered for inclusion, as well as articles that were the subject of clinical twin research or family studies.

\section{Twin Studies on CAS}

The features of carotid arteries have been the focus of many twin studies since the 1980s. The first twin studies aimed to investigate the effect of environmental factors (e.g., smoking) on atherosclerosis in monozygotic (MZ) twins discordant for smoking (Haapanen et al., 1989; Lassila et al., 1988). Recently, CIMT and plaques on several segments of the carotid artery, which are important predictors of future cardiovascular events, have been the focus of investigations in twins (Naqvi \& Lee, 2014).

Heritability of CIMT and its genetic correlation with other non-vascular traits. CIMT is the distance between the luminal surface of the intima (inner layer of the carotid artery) and the media-adventitia interface measured by ultrasound. Substantial genetic effects on CIMT have been described using the ACE + age model (Medda et al., 2014). Variance in the common CIMT was genetically determined in 31\% of participants (Medda et al., 2014). Similar results were observed in the Korean population (Lee et al., 2012a). Using the ACE model, heritability was estimated at $48 \%, 38 \%$, and $45 \%$ regarding common CIMT, bifurcation intima-media thickness (IMT), and internal CIMT, respectively. When taking into account measured covariates (cardiovascular risk factors), the variance was explained by additive genetics in $21 \%$ in the common carotid artery (CCA) and $24 \%$ in the bifurcation and in $31 \%$ in the internal carotid artery (ICA) (Lee et al., 2012a). Cardiovascular risk factors determined the total phenotypic variance in $46 \%, 37 \%$, and $26 \%$ in the CCA, bifurcation IMT, and ICA, respectively (Lee et al., 2012a). Zhao et al. (2008) reported higher heritability (69\%) of CIMT, assuming equal common environmental factors, and the heritability remained high (59\%) after adjusting for age, high-density lipoprotein (HDL), and systolic blood pressure (SBP). However, the study population consisted only of middle-aged male twins. Swan et al. (2003) found higher MZ than dizygotic correlations regarding far-wall common CIMT, but the significant heritability was not confirmed. Near-wall common CIMT on the right side did not show a higher MZ correlation (Swan et al., 2003); however, far-wall common CIMT is the preferred location to determine CIMT (Wikstrand, 2007). The differences observed among segments of the carotid arteries might be attributable to the carotid geometry (Bijari et al., 2014; Phan et al., 2012). Furthermore, Polak et al. (2010) suggested that there is a segmental difference regarding effects of cardiovascular risk factors on the carotid arteries. According to their results, fasting glucose and diastolic blood pressure showed a stronger association with common CIMT than with the other segments. Hypertension, diabetes, and current smoking were associated with carotid bulb IMT, and low-density lipoprotein (LDL) cholesterol with ICA IMT (Polak et al., 2010).

Interestingly, the association of anthropometric parameters showed differences in genetic basis between men and women. In men, the genetic correlation between body mass index (BMI) and IMT in the common and internal carotid arteries remained significant even after adjustment for covariates, whereas in women, these traits did not genetically correlate with CIMT after adjustment (Song et al., 2012). Similarly, Juo et al. (2004) found genetic correlation between common CIMT and BMI in a family study conducted on the Hispanic population. In a study conducted on women twin pairs, substantial additive genetic basis (92\%) was found regarding the association between carotid-femoral pulse wave velocity and CIMT (Cecelja et al., 2011). However, no independent association was found between these two traits (Cecelja et al., 2011). Kulshreshtha et al. (2014) implied that cardiovascular health index (which considers blood pressure, fasting glucose, total cholesterol, BMI, physical activity, healthy diet, and smoking) and CIMT are independently associated and this relation has a unique environmental basis. 
TABLE 1

Heritability Values for CAS Markers in Twin Studies

\begin{tabular}{|c|c|c|c|}
\hline \multirow[b]{2}{*}{ Author } & \multicolumn{3}{|c|}{ Twin studies } \\
\hline & Variable & Heritability & Adjustment for covariates \\
\hline \multirow[t]{2}{*}{ Medda et al. (2014) } & \multicolumn{3}{|c|}{ Model: ACE + age } \\
\hline & CCA IMT & $31 \%$ & Sex, SBPao \\
\hline \multirow[t]{4}{*}{ Lee et al. (2012a) } & \multicolumn{3}{|c|}{ Model: ACE + covariates } \\
\hline & CCA IMT & $21 \%$ & Age, BMI, diabetes, hypertension \\
\hline & Bifurcation IMT & $24 \%$ & Age, sex, alcohol use, diabetes hypertension \\
\hline & ICA IMT & $31 \%$ & Age, sex, BMI \\
\hline \multirow[t]{3}{*}{ Lee et al. (2012b) } & CCA IMT & $47 \%$ & \multirow{3}{*}{$\begin{array}{l}\text { Sex, FRS, study site, alcohol consumption, exercise, BMI, } \\
\text { triglycerides and high-sensitivity C-reactive protein }\end{array}$} \\
\hline & ICA IMT & $45 \%$ & \\
\hline & Bifurcation IMT & $36 \%$ & \\
\hline Zhao et al. (2008) & CCA IMT & $59 \%$ & Age, HDL, SBP \\
\hline \multirow[t]{5}{*}{ Swan et al. (2003) } & \multicolumn{2}{|c|}{ Non-significant, raw heritability estimates } & Age, sex, height, blood pressure \\
\hline & Right CCA far wall mean IMT & $31 \%$ & \\
\hline & Right CCA far wall max IMT & $19 \%$ & \\
\hline & Left CCA far wall mean & $2 \%$ & \\
\hline & Left CCA far wall max & $26 \%$ & \\
\hline \multirow[t]{2}{*}{ Lucatelli et al. (2017) } & A-E model & & \multirow[t]{2}{*}{ Age and country } \\
\hline & Presence of carotid plaque & $52 \%$ & \\
\hline \multirow[t]{8}{*}{ Tarnoki et al. (2012) } & ACE-model & & \multirow[t]{8}{*}{ Age-, sex-, and country-adjusted } \\
\hline & Plaque area & $69 \%$ & \\
\hline & Plaque sidedness & $74 \%$ & \\
\hline & Plaque quantity & $74 \%$ & \\
\hline & Presence of carotid plaque in CCA & $78 \%$ & \\
\hline & Presence of carotid plaque in bulb & $68 \%$ & \\
\hline & Presence of carotid plaque in ICA & $66 \%$ & \\
\hline & Plaque composition & $74 \%$ & \\
\hline
\end{tabular}

Note: ACE-model: $\mathrm{A}=$ additive genetic effects, $\mathrm{C}=$ shared environment effects, $\mathrm{E}=$ unshared environment effects, $\mathrm{BMI}=$ body mass index, $\mathrm{CCA}=$ common carotid artery, FRS = Framingham Risk Score, HDL = high-density lipoprotein, ICA = internal carotid artery $\mathrm{IMT}=$ intimamedia thickness, MAP = mean arterial pressure, RSES = Rosenberg Self-Esteem Scale, SBPao = aortic systolic blood pressure, $\mathrm{SBP}=$ systolic blood pressure.

Heritability of carotid artery plaque features. On a relatively large sample (328 individuals) of Hungarian and Italian twins, additive genetics was responsible for the variance in the presence of carotid plaques in $52 \%$ of participants, and this trait was explained by unique environmental factors in $48 \%$ (Lucatelli et al., 2017). Moreover, substantial relation in the co-occurrence of femoral and carotid plaques was found using the Cholesky model (42\%) and was highly heritable (77\%) (Lucatelli et al., 2017). Besides, the contribution of unique environmental factors to co-occurrence of these plaques was lower but not negligible (23\%) (Lucatelli et al., 2017). The same study group reported an even higher additive genetic basis of carotid plaque presence (78\%), plaque composition (74\%), plaque sidedness (74\%), and plaque quantity (74\%) (Tarnoki et al., 2012). Although heritability seems to have a strong influence on both CIMT and carotid plaques, there are twin studies emphasizing the role of mainly non-shared environmental factors. Investigating co-twins living in different countries is an ideal model to assess unique environmental effects. Jartti et al. (2009) described interesting results when comparing CIMT in Finnish twin pairs when one co-twin was resident in Sweden. Being a resident in a lower coronary heart disease risk country had a significant impact on CIMT, but the difference was only significant when moving at an age less than 21 years (Jartti et al., 2009). On the other hand, the genetic susceptibility to have a greater CIMT in certain populations is also confirmed by the results of the same study group, showing that men from Eastern Finland had significantly higher IMT compared to men from Western Finland, and this was independent from their current resident country (Jartti et al., 2002). Table 1 summarizes the twin studies and heritability values on carotid plaque features and CIMT.

Proust et al. (2015) conducted an exome-array analysis and reported a heritability of $10.6 \%$ attributable to variants on the exome-array regarding common CIMT using genome-wide complex trait analysis (GCTA). However, despite the significant heritability, the large standard errors may indicate inconclusive results. None of the investigated exomes reached the significance thresholds in this study (Proust et al., 2015). GCTA is a tool to investigate heritability of phenotypes based on the differences in genotype data between cases and controls (Yang et al., 2011). According to our knowledge, no heritability was estimated using LD score regression for CIMT phenotypes.

Family studies and CAS. Although twin studies are the focus of this article, family studies in regard to CAS also have to be mentioned in brief. In family studies, the heritability of CIMT varied between $16 \%$ and $66 \%$ (Fox et al., 2003; Juo et al., 2005; Kao et al., 2005; Kuipers et al., 2013; Mayosi et al., 2005; Moskau et al., 2005; Ryder et al., 2017; Sayed-Tabatabaei et al., 2005; Xiang et al., 2002). There were two findings for heritability of plaque presence of $23 \%$ (Hunt et al., 2002) and 15\% (Dong et al., 2010). Whether 
heritability is calculated for offspring only or offspring and parents influences the results heavily. The population characteristics - for example, hypertensive or diabetic individuals - also may explain the wide range of heritability results. Although the family study is a good method to assess the difference between generations, it may not differentiate shared environmental and genetic effects, and this can be a cause of differences compared to twin studies (Susser \& Susser, 1987). Table 2 summarizes the family and sib studies and heritability values on carotid plaque features and CIMT.

The methodology of CIMT measurement may be responsible for the observed differences in heritability values. Far-wall CIMT values are preferred over near-wall CIMT values as layers of the near-wall cannot be accurately visualized and clearly distinguished because the ultrasound beam crosses the arterial wall layers in a different order (from high to low echogenic structures) as compared to farwall CIMT. Far-wall CIMT, on the other hand, is highly correlated with wall thickness measurements on histological specimens (Pignoli et al., 1986; Wong et al., 1993). Differences also arise in carotid artery segments, as visualization of the CCA is more accurate compared to visualization of the carotid bulb and ICA. This is explained by the CCA being perpendicular to the ultrasound beam. Mean CIMT values have the advantage of better reproducibility; however, they are less sensitive to changes in CIMT (Stein et al., 2008). Most protocols are made for the registration of CCA far-wall mean IMT. On the contrary, plaques should be screened and registered on the CCA, carotid bulb and ICA segments separately (Stein et al., 2008).

Other non-modifiable factors, such as gender and ethnic differences, have to be considered when interpreting heritability results of CIMT. Several studies have confirmed that male gender is associated with significantly higher CIMT values both in adults (Mazurek et al., 2014) and children (Whincup et al., 2012). Relevant ethnic differences have been observed, with Black African Caribbeans having significantly higher CIMT compared to White Europeans (Markus et al., 2001; Whincup et al., 2012). Significantly higher CIMT values were reported among African-American individuals as compared to Whites and Asians (Breton et al., 2011). Furthermore, the impact of significant covariates on a given phenotype should always be taken into account when interpreting heritability results. Similar heritability estimates with and without adjustment for covariates indicate a more powerful heritability result and the effect of the covariates on the variance. Different models may be created based on the significantly associated covariates. For example, features of carotid plaque were highly heritable when adjusting for age, sex, and country only; when taking into account significant covariates, such as smoking, hyperlipidemia, peripheral arterial disease, and diabetes, the heritability did not change significantly (Tarnoki et al., 2012).

\section{Genes Associated with Carotid Artery Atherosclerosis}

Heritability of carotid artery atherosclerosis traits has been confirmed by the twin and family studies described above in detail, even though the results show great variation in heritability values depending on the methods and the populations investigated. In order to obtain a more detailed understanding of the genes beyond phenotype-based heritability, various studies investigating the exact gene variations have been conducted via linkage analysis, candidate gene association studies, and GWAS. These studies aim to determine the risk or the eventual causative role of specific alleles regarding the CAS phenotype; however, differences between these study designs have to be emphasized. Candidate gene association studies depend heavily on the right choice of genes, which can bias the outcomes. This approach may be successful if there is a presumption or knowledge about the function of the gene of interest. GWAS, on the other hand, can be conducted in order to find an association between a phenotype or disease and genetic variants without any prior knowledge on the function or action of a given gene. GWASs allow the sequencing of the entire genome, and therefore, are less biased by the choice of candidate genes. Furthermore, GWAS is a more powerful method to identify low-penetrance variants. This is also the reason why GWAS studies are well-established methods for the investigation of the genetic background of common genetic variations and complex diseases and phenotypes, such as CIMT and plaque. On the other hand, GWASs are not suitable for the analysis of the genetic background of rare diseases (Wilkening et al., 2009). Compared to linkage analysis, GWAS has a better resolution. Previous reviews summarized the most relevant genes and single-nucleotide polymorphisms (SNP) (Humphries \& Morgan, 2004; Juo, 2009). Therefore, the current review is restricted to the advances and most relevant studies in this field since the latest reviews (Humphries \& Morgan, 2004; Juo, 2009).

\section{Candidate Gene Analyses and GWAS on CAS}

Since atherosclerosis is a complex procedure, prior candidate gene association studies aimed to investigate regulators of the process at several points, such as inflammation and the function of extracellular matrix components.

The matrix-metalloproteinase-3 (MMP-3) and other matrix-metalloproteinases (MMPs). Members of the MMP family, which are important regulators of the extracellular matrix degradation, were investigated as target genes influencing atherogenesis in both coronary and carotid arteries. The MMP-3 enzyme has broad substrate specificity in extracellular matrix degradation and can regulate other MMPs (Woessner, 1991). Extensive research has been conducted on the $5 \mathrm{~A} / 6 \mathrm{~A}$ polymorphisms found in the promoter region of the MMP-3 gene with regard to both coronary and CAS, as the 5A allele is associated with higher and the $6 \mathrm{~A}$ allele with lower MMP-3 
TABLE 2

Heritability Values for CAS and Stiffness Markers in Family- and Sib-Studies

\begin{tabular}{|c|c|c|c|}
\hline \multirow[b]{2}{*}{ Author } & \multicolumn{3}{|c|}{ Family studies } \\
\hline & Variable & Heritability & Adjustment for covariates \\
\hline Chen et al. (2008) & CCA IMT & $37 \%$ & Age, sex, BMl \\
\hline Li et al. (2013) & CCA IMT & $47 \%$ & Age, sex \\
\hline \multirow[t]{8}{*}{ Juo et al. (2004) } & Total maximum IMT & $40 \%$ & Age, sex \\
\hline & Total mean IMT & $36 \%$ & \\
\hline & CCA maximum IMT & $35 \%$ & \\
\hline & CCA mean IMT & $39 \%$ & \\
\hline & Bifurcation maximum IMT & $25 \%$ & \\
\hline & Bifurcation mean IMT & $26 \%$ & \\
\hline & ICA maximum IMT & $9 \%$ & \\
\hline & ICA mean IMT & $12 \%$ & \\
\hline \multirow[t]{2}{*}{ Xiang et al. (2002) } & Offspring & $64 \%$ & Offspring: age, fasting glucose, and insulin sensitivity, SBP \\
\hline & Parents to offspring & $34 \%$ & Parents to offspring: age, SBP, total cholesterol, sex \\
\hline Kao et al. (2005) & CCA IMT & $16 \%$ & Age, sex \\
\hline \multirow[t]{6}{*}{ Kuipers et al. (2013) } & Mean CCA IMT & $47 \%$ & Residual heritability \\
\hline & Max CCA IMT & $35 \%$ & \\
\hline & Mean AD & $64 \%$ & \\
\hline & Max AD & $62 \%$ & \\
\hline & Mean LD & $58 \%$ & \\
\hline & Min LD & $57 \%$ & \\
\hline \multirow[t]{2}{*}{ Dong et al. (2010) } & Plaque presence & $50 \%$ & Plaque presence: Age, diabetes, smoking, BMI, hypertension \\
\hline & Plaque area & $17 \%$ & $\begin{array}{l}\text { Plaque area: Age, diabetes, smoking, BMI, and hypertension, } \\
\text { age }^{2} \text { WHR }\end{array}$ \\
\hline Mayosi et al. (2005) & $\log _{e}$ maximal CCA IMT & $24 \%$ & Age, sex, body mass index, physical exercise \\
\hline \multirow[t]{3}{*}{ North et al. (2002) } & CCA lumen diameter & $44 \%$ & CCA lumen diameter: sex, age, center, diabetes, \\
\hline & CCA IMT & $21 \%$ & hypertension, BSA \\
\hline & & & CCA IMT: sex, age, smoking, diabetes \\
\hline \multirow[t]{4}{*}{ Fox et al. (2003) } & CCA mean IMT & $38 \%$ & Age, sex, systolic blood pressure, number of cigarettes/day, \\
\hline & CCA maximum IMT & $39 \%$ & total cholesterol, HDL cholesterol, triglycerides, diabetes \\
\hline & ICA mean IMT & $35 \%$ & status, body mass index, anti-hypertensive treatment, \\
\hline & ICA maximum IMT & $31 \%$ & menopausal status, and hormone replacement therapy \\
\hline Hunt et al. (2002) & Carotid artery plaque & $23 \%$ & $\begin{array}{l}\text { Age, sex, BMI, BMI, waist circumference, diabetes, } \\
\text { hypertension, and smoking status }\end{array}$ \\
\hline \multirow[t]{2}{*}{ Wang et al. (2005) } & $\begin{array}{l}\text { CCA IMT unadjusted } \\
\text { CCA IMT adjusted for sex and age }\end{array}$ & $\begin{array}{l}68 \% \\
45 \%\end{array}$ & $\begin{array}{l}\text { Multivariate-adjusted: gender, age, age }{ }^{2} \mathrm{SBP} \text {, fasting insulin, } \\
\text { and smoking }\end{array}$ \\
\hline & CCA IMT multivariate-adjusted & $40 \%$ & \\
\hline \multirow[t]{4}{*}{$\begin{array}{l}\text { Sayed-Tabatabaei } \\
\text { et al. (2005) }\end{array}$} & $\begin{array}{l}\text { CCA IMT adjusted for age and } \\
\text { gender }\end{array}$ & $61 \%$ & $\begin{array}{l}\text { 1. CCA IMT covariates: age, gender, mean arterial pressure, } \\
\text { LDL cholesterol, fasting glucose, and heart rate }\end{array}$ \\
\hline & $\begin{array}{l}\text { CCA IMT adjusted for other } \\
\text { covariates }\end{array}$ & $66 \%$ & $\begin{array}{l}\text { 2. Plaque score covariates: age, gender, body mass index, } \\
\text { systolic blood pressures, LDL and HDL cholesterol, and }\end{array}$ \\
\hline & $\begin{array}{l}\text { Plaque score adjusted for age and } \\
\text { gender }\end{array}$ & $40 \%$ & smoking. \\
\hline & $\begin{array}{l}\text { Plaque score adjusted for other } \\
\text { covariates }\end{array}$ & $44 \%$ & \\
\hline Ryabikov et al. (2007) & CCA IMT & $54 \%$ & Model 1: age, sex, race \\
\hline \multirow[t]{3}{*}{ Lange et al. (2002) } & CCA IMT (model 1) & $31 \%$ & Model 2: age, sex, race, total cholesterol \\
\hline & CCA IMT (model 2) & $36 \%$ & Model 3: age, sex, race, total cholesterol, hypertension \\
\hline & CCA IMT (model 3) & $41 \%$ & status, current smoking status \\
\hline Chien et al. (2008) & CCA IMT & $19 \%$ & \\
\hline \multirow[t]{3}{*}{ Moskau et al. (2005) } & CCA IMT (model 1) & $61 \%$ & Model 1: age, sex, arterial hypertension, diabetes mellitus, \\
\hline & CCA IMT (model 2) & $26 \%$ & Lipoprotein a \\
\hline & & & Model 2: age, sex, arterial hypertension, diabetes mellitus \\
\hline Bella et al. (2013) & Carotid artery lumen diameter & $\begin{array}{l}28-56 \% \text { in } \\
\text { various } \\
\text { centers }\end{array}$ & Sex, age \\
\hline \multirow[t]{9}{*}{ Ryder et al. (2017) } & Whole cohort & & Whole cohort: age, sex, race, BMI, MAP, and smoking of \\
\hline & Lumen diameter & $55 \%$ & both parents and offspring \\
\hline & CCA IMT & $29 \%$ & Complete trios: Age, sex, race, $\mathrm{BMI}, \mathrm{MAP}$, and smoking of \\
\hline & Diameter distensibility & $28 \%$ & both parents and offspring \\
\hline & Cross-sectional distensibility & $27 \%$ & \\
\hline & Diameter compliance & $3 \%$ & \\
\hline & Cross-sectional compliance & $27 \%$ & \\
\hline & Among complete trios & & \\
\hline & Lumen diameter & $58 \%$ & \\
\hline
\end{tabular}


TABLE 2

Continued

\begin{tabular}{llll}
\hline & & \multicolumn{2}{c}{ Family studies } \\
\cline { 2 - 4 } Author & Variable & Heritability & Adjustment for covariates \\
\hline $\begin{array}{c}\text { Rampersaud et al. } \\
\text { (2008) }\end{array}$ & CCA IMT & $29 \%$ & Age, sex \\
Sacco et al. (2009) & Mean Total IMT & $65 \%$ & Mean total and mean bifurcation IMT, max total IMT, and \\
& Mean Bifurcation IMT & $58 \%$ & max ICA IMT: Age, age 2 , sex, PackYears, WHR, BMI \\
& Mean ICA IMT & $47 \%$ & Mean ICA IMT: Age, age ${ }^{2}$, sex, hypercholesterolemia, \\
& Mean CCA IMT & $56 \%$ & WHR, BMI \\
& Max Total IMT & $62 \%$ & Mean CCA IMT: Age, sex, hypertension, diabetes, \\
& Max Bifurcation IMT & $51 \%$ & PackYears, WHR BMI \\
& Max ICA IMT & $41 \%$ & Max bifurcation IMT: Age, age ${ }^{2}$, sex, age by sex, \\
& Max CCA IMT & $48 \%$ & PackYears, WHR, BMI \\
& & Sib-study & Max CCA IMT: Age, sex, hypertension, \\
Duggirala et al. (1996) & hypercholesterolemia, diabetes, PackYears, WHR, BMI & \\
\hline & CCA IMT & $92 \%$ & Age, diabetes mellitus, SBP, TC, and HDL cholesterol \\
\hline
\end{tabular}

Note: $\mathrm{AD}=$ adventitial diameter, $\mathrm{BMI}=$ body mass index, $\mathrm{BSA}=$ body surface area, $\mathrm{CCA}=$ common carotid artery, $\mathrm{HDL}=\mathrm{high}$-density lipoprotein, ICA = internal carotid artery, IMT = intima-media thickness, $L D=$ lumen diameter, LDL = low-density lipoprotein, MAP $=$ mean arterial pressure, $\mathrm{SBP}=$ systolic blood pressure, $\mathrm{TC}=$ total cholesterol, $\mathrm{WHR}=$ waist-hip ratio.

transcription (Ye et al., 1996), the former leading to decreased plaque stability and the latter leading to (stable) plaque progression. The $5 \mathrm{~A}$ variant seems to be related to coronary plaque rupture and consequent myocardial infarction and the $6 \mathrm{~A}$ variant may be related to coronary artery disease (Abilleira et al., 2006). Increased levels of MMP-3 have been described in patients with vulnerable plaques in a recent study (Hu et al., 2018), which is in line with the aforementioned assumption regarding the effect of the 5A variant. The MMP-3 6A allele was significantly associated with greater IMT (Rauramaa et al., 2000), even after adjustment for covariates (Djuric et al., 2008; Rundek et al., 2002). This was confirmed by a meta-analysis including roughly 180 individuals (Humphries \& Morgan, 2004). Recent results also indicate that the $5 \mathrm{~A} / 6 \mathrm{~A}$ polymorphism is associated with CIMT progression in patients with type 2 diabetes mellitus (Pleskovic et al., 2017). A recent GWAS study identified four SNPs on the 11q22.3 region that were independently associated with plasma MMP-12 levels on a genome-wide significant level, but expression quantitative trait loci analysis did not reveal a direct, causative role of these SNPs (Mahdessian et al., 2017). MMP-8 promoter gene polymorphisms were associated with plaque presence in Caucasian females and elevated MMP-8 mRNA levels in carotid artery plaques were associated with this allele ex vivo; however, the power of this study was limited by the low number of cases (Djuric et al., 2011). Other MMPs and their gene polymorphisms, such as MMP-14 (Li et al., 2014) and MMP-7 (Hu et al., 2011; Wang et al., 2011), might have a role in plaque vulnerability, but these results have not been confirmed on larger populations.

CDKN2A/B. CDKN2A and $2 B$ are important modulators of cell proliferation. Zhang et al. (2015) identified the association between the SNP near the $C D K N 2 A / B$ gene and carotid artery calcification in a population of nearly 900 individuals. The same SNP was significantly associated with plaque presence in a meta-analysis conducted on a much larger sample (den Hoed et al., 2015). The $C D K N 2 A / B$ gene is located at the 9p21 locus, which is subject of intensive research and the relevance of which in atherosclerosis is undoubted (Holdt \& Teupser, 2012; Holdt et al., 2010, 2011, 2013, 2016). Results of genome-wide significance of this polymorphism were replicated by large-scale meta-analyses investigating its relation to coronary heart disease (Nikpay et al., 2015) and carotid plaque score (Pott et al., 2017). The $C D K N 2 A / B$ polymorphism was strongly associated with carotid plaque score (Pott et al., 2017), but not with CIMT in a large-scale, multi-ethnic candidate gene association study conducted on more than 8,000 individuals (Vargas et al., 2016), which raises the possibility of clinical and subclinical atherosclerosis having a partly different genetic background (Holdt \& Teupser, 2012).

IL-6 (interleukin-6) and IL-10 (interleukin-10). Great attention has been dedicated to inflammatory molecules and variations of their genes in the atherogenic process. The role of IL- 6 and IL-10 was reviewed previously and conflicting results were found (Humphries \& Morgan, 2004). Although it is logical that the genetic variants coding these inflammatory molecules affect CAS, results are conflicting regarding IL-6 (Chapman et al., 2003; Mayosi et al., 2005) and IL-10 (Heiskanen et al., 2010; Yu et al., 2015), and epigenetic regulatory mechanisms are possible (Pessi et al., 2015). In a family study of roughly 800 individuals, the functional polymorphism of IL-6 explained 2.5\% of the heritable component of CIMT (Mayosi et al., 2005). Hulkkonen et al. (2009) and Riikola et al. (2009) did not find any association between CIMT and IL- 6 gene polymorphisms in a gene-association study of $\sim 2,000$ individuals. Cunnington et al. (2009) could not demonstrate the association between IL-6 gene polymorphisms (which had been associated with coronary artery disease) and CIMT. 
Since the IL-10 is a molecule of potent anti-inflammatory character, it may have therapeutic implications in the future through gene therapy and is a subject of animal model studies (Dronadula et al., 2017; Du et al., 2011).

APOE. Although earlier studies emphasize the role of the E4 genotype of the APOE gene in carotid artery atherosclerosis and the atheroprotective role of the E2 genotype (Humphries \& Morgan, 2004; Paternoster et al., 2010), large-scale meta-analyses did not confirm the relevance of this gene regarding CIMT. Instead of the APOE gene, the APOC1 gene was associated with CIMT (Bis et al., 2011; Geisel et al., 2016). The authors speculate whether the significance of $A P O E$ gene may be restricted to early atherosclerosis and familial dyslipidemia (Bis et al., 2011).

$A C E$. The $A C E$ gene codes the angiotensin-converting enzyme which converts angiotensin I to angiotensin II. A wellknown association exists between the enzyme and hypertension. The insertion/deletion (I/D) in the non-coding region of this gene affecting the enzyme activity has been associated with increased CIMT. A meta-analysis including more than 9,800 individuals described the significant positive association between the D-allele and CIMT (SayedTabatabaei et al., 2003). The association was significant only among Whites in low-risk populations, whereas it was significant among both Asians and Whites in highrisk populations (including symptomatic cerebrovascular disease, type I and II diabetes, non-diabetic hemodialysis, and hypertensive patients), indicating relevant ethnic differences possibly in both genetic and environmental effects regarding this trait (Sayed-Tabatabaei et al., 2003). The D/D genotype had a low frequency amongst Asians (Sayed-Tabatabaei et al., 2003). Several other studies with smaller hypertensive populations from both Asian (Park et al., 2009) and European (Imbalzano et al., 2017) ancestries found association between the $\mathrm{D} / \mathrm{D}$ phenotype and increased CIMT. Some other studies found no significant association with this trait (Hung et al., 1999), which may depend on smaller sample sizes or other methodological aspects as an association of opposite direction has not been described (Humphries \& Morgan, 2004).

Paraoxonase-1 (PON-1). PON-1 is an enzyme that binds to plasma HDL and protects it from oxidation (Litvinov et al., 2012). PON-1 may affect CAS through its influence on HDL (Kim et al., 2016) and LDL particles (Mackness et al., 1998). The genetic variants and expression of the $P O N-1$ gene is highly dependent on environmental influences, such as smoking, and it has been a subject of research regarding epigenetic effects (Aviram \& Vaya, 2013). Details regarding $P O N-1$ polymorphisms and CAS have recently been reviewed (Lioudaki et al., 2017), and therefore, they are not further discussed in this article. Briefly, two polymorphisms of the enzyme gene have been described and their effect on CIMT and carotid plaque formation is controversial (Humphries \& Morgan, 2004; Lioudaki et al., 2017).

Cholestryl-esther transfer protein (CETP). CETP is a protein taking part in the cholesterol transport from HDL to very low-density lipoprotein. The inhibition of CETP increases serum HDL levels, and therefore, it is a potential pharmacological target. Millwood et al. (2018) investigated the association between the loss-of-function CETP variant and CIMT. Furthermore, a genetic risk score was created consisting of the loss-of-function variant and four other CETP variants and its relation to CIMT was studied. No significant associations were found in this study involving more than 20,000 Asian individuals (Millwood et al., 2018). Two polymorphisms of the enzyme gene, the TaqIB, and the I405V polymorphisms, have been studied but the results are inconclusive regarding their relation to CIMT (Humphries \& Morgan, 2004). A meta-analysis conducted on circa 2,200 individuals did not find any association between these polymorphisms and CIMT either in the total population of the meta-analysis, nor in Asians and Europeans separately (Li et al., 2014). Neither TaqIB nor other rare variants showed significant associations with CIMT in a study including 855 patients from different ethnicities, despite the fact that serum HDL and CETP levels depended on CETP polymorphisms (Tsai et al., 2008).

MTHFR. MTHFR is involved in homocysteine metabolism and the $\mathrm{C}$ to $\mathrm{T}$ substitution at nucleotide 677 in the MTHFR gene has been associated with lower enzyme activity and higher homocysteine levels (Miyaki, 2010). Increased homocysteine levels are associated with higher cardiovascular risk (Graham et al., 1997). Previous reviews have summarized the findings regarding MTHFR gene polymorphisms (Humphries \& Morgan, 2004; Juo, 2009). The association between the MTHFR gene and homocysteine levels is confirmed, but recent candidate gene studies including less than 1,000 individuals did not confirm the gene's direct effect on CIMT (HernandezSocorro et al., 2017; Pramukarso et al., 2015; Sun et al., 2017). Whether hyperhomocysteinemia is directly or indirectly related to atherosclerosis (the latter because of renal dysfunction) is to be elucidated (Durga et al., 2004).

Other genes. Further novel findings of large-scale metaanalyses include the role of certain SNPs of the EDNRA gene (coding the endothelin receptor type-1) in multiple carotid artery plaque phenotypes (Bis et al., 2011; Hemerich et al., 2015). Regarding the relation of EDNRA gene to CIMT, the results are controversial (Li et al., 2015; LopezMejias et al., 2014); however, gene-environmental interactions regarding this gene have been studied (Li et al., 2015; 2015). Another gene, PINX1, the product of which is a telomerase inhibitor, was associated with common CIMT 
in the general population (Bis et al., 2011; Geisel et al., 2016; Li et al., 2015), although no similar association was found in a population with rheumatoid arthritis (Lopez-Mejias et al., 2014). The SMG6 gene showed significant association with common CIMT with increased heterogeneity across ethnicities, whereas LPA and TRIB1 loci were significantly associated with internal CIMT (Vargas et al., 2016).

In the Asian population, the highly significant association between Early B-cell Factor 1 (EBF1) gene SNPs and CIMT progression was emphasized in a large-scale GWAS study (Xie et al., 2015), but other results point toward the epigenetic regulation of this gene and its effect on atherosclerosis (Singh et al., 2015). In the same study, another SNP near the procadherin 15 (PCDH15) gene was linked to CIMT progression on a genome-wide significant level (Xie et al., 2015), and although other similar SNPs in this region have been identified, the relevance of this SNP is not confirmed.

More recently, the ryanodine receptor 3 (RYR3) gene SNPs and their relation to CAS have been investigated. This gene codes a calcium channel regulating intracellular calcium and inflammatory processes. Two variants of this gene showed an association with subclinical and clinical CAS in a subpopulation of men (Shrestha et al., 2010), women (Shendre et al., 2014), and a population of both sexes (Zhi et al., 2015) suffering from human immunodeficiency virus (HIV) as well as clinical manifestation of CAS in a postmortem study of Japanese elderly (Zhao et al., 2014).

Bis et al. (2011) conducted a GWAS meta-analysis on $\sim 25,000, \sim 11,000$, and $\sim 10,000$ individuals regarding carotid artery plaque, internal CIMT, and common CIMT, respectively. Three SNPs reached genome-wide significance regarding common CIMT, including a SNP near the ZHX2 gene on chromosome 8q24, a SNP near the APOC1 gene on chromosome 19q13, and a SNP within the PINX1 gene on 8q23.1. The first two SNPs were associated with decreased common CIMT. More specifically, the rs11781551 near the ZHX2 gene lowered CIMT by $0.8 \%$ per copy of the allele, and the G allele of rs445925 near the APOC1 gene lowered common CIMT by $1.6 \%$. The G allele on the third SNP near the PINX1 gene, rs6601530, was associated with increased common CIMT by $0.08 \%$ per allele copy. Two SNPs near the PIK3CG and EDNRA genes were associated with plaque presence on a genome-wide significant level. No SNP achieved genome-wide significant association with regard to internal CIMT (Bis et al., 2011).

Melton et al. (2013) investigated SNPs associated with CIMT in 772 Mexican American individuals. No genomewide significant association was detected, but there were some nominally significant SNPs on chromosome 20p11 near the gene $P A X 1$ and on chromosome $2 \mathrm{q} 21$ in the gene NCKAP5 (Nck-associated protein 5) in relation to internal CIMT. Another SNP upstream of EXOC3L2 on chromosome 19q13 was nominally significantly associated with common CIMT. The number of cases was small in this study and therefore the study power was relatively low. There was a genetic correlation of $51 \%$ between common and internal CIMT, indicating that the genetic basis of these two segments CIMT is partly overlapping (Melton et al., 2013).

Shendre et al. (2017) performed genome-wide association and admixture analysis on CIMT-related genes in a population of $\sim 1,000$ individuals including HIVpositive and negative African-American female individuals (Shendre et al., 2017). None of the SNPs reached genomewide significance, although some SNPs almost reached this level, such as mediator complex subunit 30 and exostosin glycosyltransferase 1 (MED30 and EXT1) genes on chromosome 8 in all women and in the HIV-positive group, catenin delta 2 (CTNND2) gene on chromosome 5, transmembrane and coiled-coil domain family 3 gene, and the NADH: Ubiquinone oxidoreductase subunit A12 (TMCC3 and NDUFA12) in the HIV-positive group and family with sequence similarity 5 , member $\mathrm{C}$, and regulator of G-protein signaling 18 genes (FAM5C and RGS18) on chromosome 1 in the HIV-negative group. CTNND2 and TMCC3 $\mid N D$ UFA12 were significantly associated with local European ancestry. However, the study power was relatively low because of the number of cases (Shendre et al., 2017). The relevance of these novel findings remains to be elucidated.

\section{Other GWAS in Relation to CAS (Genetic Risk Score)}

Large-scale studies attempted to find associations between certain risk scores and SNPs previously identified by GWAS.

Den Hoed et al. (2015) investigated the association between genetic risk score consisting of 45 genes and carotid plaque and CIMT in a meta-analysis involving more than 7,000 individuals. The risk alleles of these 45 loci had previously been associated with coronary heart disease. Carotid bulb CIMT and plaque presence showed significant associations with the genetic risk score, but not CCA IMT (den Hoed et al., 2015). Each risk allele of the 45 loci increased the odds of having plaque by $2.8 \%$ and that of having increased CIMT by $0.24 \%$ (den Hoed et al., 2015). SNPs near $C D K N 2 B / A$ were significantly associated with plaque presence, but this large-scale meta-analysis failed to demonstrate any such association between plaque presence and SNPs near EDNRA. Furthermore, additional risk-alleles on chromosome $9 \mathrm{p} 21.3$, where $C D K N 2 B / A$ is located, increased the odds of having plaque with an additional $13.9 \%$. With regard to CIMT, no significant association was observed between the individual loci and CIMT of the carotid bulb or CCA; however, the association between risk alleles near the apolipoprotein gene cluster and common CIMT was confirmed (den Hoed et al., 2015). No association was found between SNPs affecting coronary artery disease and common CIMT in a meta-analysis involving roughly 5,000 individuals (Conde et al., 2011). The different outcomes regarding CIMT of the CCA and bulb might relate to 
their associations with different conditions as previously described in the literature, as CCA IMT tends to be associated with stroke whereas carotid bulb IMT tends to reflect the risk for ischemic heart disease (Ebrahim et al., 1999).

\section{Conclusion}

Although heritability varies widely regarding carotid artery atherosclerosis traits, moderate additive genetic influence seems to determine the variance in these phenotypes. Future international collaborative twin studies (such as on discordant MZ twins) should elucidate how the different environmental interventions and effects influence this genetic susceptibility in various ethnicities. The co-occurrence of CAS with coronary and peripheral atherosclerosis and other diseases have been certified with twin studies. Based on these findings, new therapeutic targets and preventive individualized strategies may be established. Numerous SNPs have been described to increase the risk for development of subclinical or clinical CAS. However, the results are often conflicting, and only a minority of these genes seems to be potential future therapeutic targets. This warrants the need for future research aiming to obtain a deeper knowledge of the exact pathomechanism of these genetic variants and gene-environmental interactions, which would be essential for practical implications of the enormous amount of genes found in GWAS-studies in relation to CAS.

\section{Conflict of Interest}

None.

\section{References}

Abilleira, S., Bevan, S., \& Markus, H. S. (2006). The role of genetic variants of matrix metalloproteinases in coronary and carotid atherosclerosis. Journal of Medical Genetics, 43, 897-901.

Aviram, M., \& Vaya, J. (2013). Paraoxonase 1 activities, regulation, and interactions with atherosclerotic lesion. Current Opinion in Lipidology, 24, 339-344.

Bella, J. N., Cole, S. A., Laston, S., Almasy, L., Comuzzie, A., Lee, E. T., ... Goring, H. H. (2013). Genome-wide linkage analysis of carotid artery lumen diameter: The Strong Heart Family Study. International Journal of Cardiology, 168, 3902-3908.

Bijari, P. B., Wasserman, B. A., \& Steinman, D. A. (2014). Carotid bifurcation geometry is an independent predictor of early wall thickening at the carotid bulb. Stroke, 45, 473478.

Bis, J. C., Kavousi, M., Franceschini, N., Isaacs, A., Abecasis, G. R., Schminke, U., ... Consortium, C. A. (2011). Metaanalysis of genome-wide association studies from the CHARGE consortium identifies common variants associated with carotid intima media thickness and plaque. $\mathrm{Na}$ ture Genetics, 43, 940-947.
Bots, M. L., Hoes, A. W., Koudstaal, P. J., Hofman, A., \& Grobbee, D. E. (1997). Common carotid intima-media thickness and risk of stroke and myocardial infarction: The Rotterdam Study. Circulation, 96, 1432-1437.

Breton, C. V., Wang, X., Mack, W. J., Berhane, K., Lopez, M., Islam, T. S., ... Avol, E. (2011). Carotid artery intimamedia thickness in college students: Race/ethnicity matters. Atherosclerosis, 217, 441-446.

Cecelja, M., Jiang, B., Bevan, L., Frost, M. L., Spector, T. D., \& Chowienczyk, P. J. (2011). Arterial stiffening relates to arterial calcification but not to noncalcified atheroma in women. A twin study. Journal of the American College of Cardiology, 57, 1480-1486.

Chambless, L. E., Folsom, A. R., Clegg, L. X., Sharrett, A. R., Shahar, E., Nieto, F. J., ... Evans, G. (2000). Carotid wall thickness is predictive of incident clinical stroke: The Atherosclerosis Risk in Communities (ARIC) Study. American Journal Of Epidemiology, 151, 478-487.

Chambless, L. E., Heiss, G., Folsom, A. R., Rosamond, W., Szklo, M., Sharrett, A. R., \& Clegg, L. X. (1997). Association of coronary heart disease incidence with carotid arterial wall thickness and major risk factors: The Atherosclerosis Risk in Communities (ARIC) Study, 1987-1993. American Journal of Epidemiology, 146, 483-494.

Chapman, C. M., Beilby, J. P., Humphries, S. E., Palmer, L. J., Thompson, P. L., \& Hung, J. (2003). Association of an allelic variant of interleukin-6 with subclinical carotid atherosclerosis in an Australian community population. European Heart Journal, 24, 1494-1499.

Chen, Y. C., Guo, X., Raffel, L. J., Xiang, A. H., Fang, B., Hsueh, W. A., ... Rotter, J. I. (2008). Carotid intima-media thickness (cIMT) cosegregates with blood pressure and renal function in hypertensive Hispanic families. Atherosclerosis, 198, 160-165.

Chien, K. L., Liau, C. S., Chen, M. F., Lee, Y. T., Jeng, J. S., Hwang, B. S., \& Su, T. C. (2008). Primary hypercholesterolemia, carotid atherosclerosis and insulin resistance among Chinese. Lipids, 43, 117-124.

Conde, L., Bevan, S., Sitzer, M., Klopp, N., Illig, T., Thiery, J., . . Markus, H. S. (2011). Novel associations for coronary artery disease derived from genome wide association studies are not associated with increased carotid intima-media thickness, suggesting they do not act via early atherosclerosis or vessel remodeling. Atherosclerosis, 219(2), 684-689. doi:10.1016/j.atherosclerosis.2011.08.031

Cunnington, M. S., Mayosi, B. M., Hall, D. H., Avery, P. J., Farrall, M., Vickers, M. A., ... Keavney, B. (2009). Novel genetic variants linked to coronary artery disease by genomewide association are not associated with carotid artery intima-media thickness or intermediate risk phenotypes. Atherosclerosis, 203, 41-44.

den Hoed, M., Strawbridge, R. J., Almgren, P., Gustafsson, S., Axelsson, T., Engstrom, G., ... Lind, L. (2015). GWASidentified loci for coronary heart disease are associated with intima-media thickness and plaque presence at the carotid artery bulb. Atherosclerosis, 239, 304-310.

Djuric, T., Stankovic, A., Koncar, I., Radak, D., Davidovic, L., Alavantic, D., \& Zivkovic, M. (2011). Association of MMP- 
8 promoter gene polymorphisms with carotid atherosclerosis: Preliminary study. Atherosclerosis, 219, 673-678.

Djuric, T., Zivkovic, M., Radak, D., Jekic, D., Radak, S., Stojkovic, L., ... Alavantic, D. (2008). Association of MMP$35 \mathrm{~A} / 6 \mathrm{~A}$ gene polymorphism with susceptibility to carotid atherosclerosis. Clinical Biochemistry, 41, 1326-1329.

Dong, C., Beecham, A., Slifer, S., Wang, L., Blanton, S. H., Wright, C. B., ... Sacco, R. L. (2010). Genomewide linkage and peakwide association analyses of carotid plaque in Caribbean Hispanics. Stroke, 41, 2750-2756.

Dronadula, N., Wacker, B. K., Van Der Kwast, R., Zhang, J., \& Dichek, D. A. (2017). Stable in vivo transgene expression in endothelial cells with helper-dependent adenovirus: Roles of promoter and interleukin-10. Human Gene Therapy, 28, 255-270.

Du, L., Dronadula, N., Tanaka, S., \& Dichek, D. A. (2011). Helper-dependent adenoviral vector achieves prolonged, stable expression of interleukin-10 in rabbit carotid arteries but does not limit early atherogenesis. Human Gene Therapy, 22, 959-968.

Duggirala, R., Gonzalez Villalpando, C., O’Leary, D. H., Stern, M. P., \& Blangero, J. (1996). Genetic basis of variation in carotid artery wall thickness. Stroke, 27, 833-837.

Durga, J., Verhoef, P., Bots, M. L., \& Schouten, E. (2004). Homocysteine and carotid intima-media thickness: A critical appraisal of the evidence. Atherosclerosis, 176, 1-19.

Ebrahim, S., Papacosta, O., Whincup, P., Wannamethee, G., Walker, M., Nicolaides, A. N., ... Lowe, G. D. (1999). Carotid plaque, intima media thickness, cardiovascular risk factors, and prevalent cardiovascular disease in men and women: The British Regional Heart Study. Stroke, 30, 841850.

Fox, C. S., Polak, J. F., Chazaro, I., Cupples, A., Wolf, P. A., D’Agostino, R. A., ... Framingham Heart, S. (2003). Genetic and environmental contributions to atherosclerosis phenotypes in men and women: Heritability of carotid intimamedia thickness in the Framingham Heart Study. Stroke, 34, 397-401.

Geisel, M. H., Coassin, S., Hessler, N., Bauer, M., Eisele, L., Erbel, R., ... Kronenberg, F. (2016). Update of the effect estimates for common variants associated with carotid intima media thickness within four independent samples: The Bonn IMT Family Study, the Heinz Nixdorf Recall Study, the SAPHIR Study and the Bruneck Study. Atherosclerosis, 249, 83-87.

Graham, I. M., Daly, L. E., Refsum, H. M., Robinson, K., Brattstrom, L. E., Ueland, P. M., .... Andria, G. (1997). Plasma homocysteine as a risk factor for vascular disease. The European Concerted Action Project. The Journal of the American Medical Association, 277, 1775-1781.

Haapanen, A., Koskenvuo, M., Kaprio, J., Kesaniemi, Y. A., \& Heikkila, K. (1989). Carotid arteriosclerosis in identical twins discordant for cigarette smoking. Circulation, 80, 1016.

Heiskanen, M., Kahonen, M., Hurme, M., Lehtimaki, T., Mononen, N., Juonala, M., ... Hulkkonen, J. (2010). Polymorphism in the IL10 promoter region and early markers of atherosclerosis: The cardiovascular risk in Young Finns Study. Atherosclerosis, 208, 190-196.

Heiss, G., Sharrett, A. R., Barnes, R., Chambless, L. E., Szklo, M., \& Alzola, C. (1991). Carotid atherosclerosis measured by B-mode ultrasound in populations: Associations with cardiovascular risk factors in the ARIC Study. American Journal Of Epidemiology, 134, 250-256.

Hemerich, D., van der Laan, S. W., Tragante, V., den Ruijter, H. M., de Borst, G. J., Pasterkamp, G., ... Asselbergs, F. W. (2015). Impact of carotid atherosclerosis loci on cardiovascular events. Atherosclerosis, 243, 466-468.

Hernandez-Socorro, C. R., Rodriguez-Esparragon, F. J., Celli, J., \& Lopez-Fernandez, J. C. (2017). Sonographic evaluation of atherosclerosis burden in carotid arteries of ischemic stroke patients and its relation to paraoxonase 1 and 2, MTHFR and AT1R genetic variants. Journal of the Neurological Sciences, 378, 146-151.

Holdt, L. M., Beutner, F., Scholz, M., Gielen, S., Gabel, G., Bergert, H., ... Teupser, D. (2010). ANRIL expression is associated with atherosclerosis risk at chromosome 9p21. Arteriosclerosis, Thrombosis, and Vascular Biology, 30, 620627.

Holdt, L. M., Hoffmann, S., Sass, K., Langenberger, D., Scholz, M., Krohn, K., ... Teupser, D. (2013). Alu elements in ANRIL non-coding RNA at chromosome 9p21 modulate atherogenic cell functions through trans-regulation of gene networks. PLOS Genetics, 9, e1003588.

Holdt, L. M., Sass, K., Gabel, G., Bergert, H., Thiery, J., \& Teupser, D. (2011). Expression of Chr9p21 genes CDKN2B (p15(INK4b)), CDKN2A (p16(INK4a)), p14(ARF)) and MTAP in human atherosclerotic plaque. Atherosclerosis, 214, 264-270.

Holdt, L. M., Stahringer, A., Sass, K., Pichler, G., Kulak, N. A., Wilfert, W., ... Teupser, D. (2016). Circular noncoding RNA ANRIL modulates ribosomal RNA maturation and atherosclerosis in humans. Nature Communications, 7 , 12429.

Holdt, L. M., \& Teupser, D. (2012). Recent studies of the human chromosome 9p21 locus, which is associated with atherosclerosis in human populations. Arteriosclerosis, Thrombosis, and Vascular Biology, 32, 196-206.

Howard, G., Sharrett, A. R., Heiss, G., Evans, G. W., Chambless, L. E., Riley, W. A., \& Burke, G. L. (1993). Carotid artery intimal-medial thickness distribution in general populations as evaluated by B-mode ultrasound. ARIC investigators. Stroke, 24, 1297-1304.

Hu, W., Wei, R., Wang, L., Lu, J., Liu, H., \& Zhang, W. (2018). Correlations of MMP-1, MMP-3, and MMP-12 with the degree of atherosclerosis, plaque stability and cardiovascular and cerebrovascular events. Experimental and Therapeutic Medicine, 15, 1994-1998.

Hu, X. F., Jin, X. P., Hu, P. Y., Zhu, M., Wang, F., Lin, X. F., ... Yang, L. H. (2011). Association of a functional polymorphism in the MMP7 gene promoter with susceptibility to vulnerable carotid plaque in a Han Chinese population. Clinical Chemistry and Laboratory Medicine, 49, 1735-1741. 
Hulkkonen, J., Lehtimaki, T., Mononen, N., Juonala, M., HutriKahonen, N., Taittonen, L., ... Kahonen, M. (2009). Polymorphism in the IL6 promoter region is associated with the risk factors and markers of subclinical atherosclerosis in men: The cardiovascular risk in Young Finns Study. Atherosclerosis, 203, 454-458.

Humphries, S. E., \& Morgan, L. (2004). Genetic risk factors for stroke and carotid atherosclerosis: Insights into pathophysiology from candidate gene approaches. Lancet Neurology, 3, 227-235.

Hung, J., McQuillan, B. M., Nidorf, M., Thompson, P. L., \& Beilby, J. P. (1999). Angiotensin-converting enzyme gene polymorphism and carotid wall thickening in a community population. Arteriosclerosis, Thrombosis, and Vascular Biology, 19, 1969-1974.

Hunt, K. J., Duggirala, R., Goring, H. H., Williams, J. T., Almasy, L., Blangero, J., ... Stern, M. P. (2002). Genetic basis of variation in carotid artery plaque in the San Antonio Family Heart Study. Stroke, 33, 2775-2780.

Imbalzano, E., Vatrano, M., Quartuccio, S., Di Stefano, R., Aragona, C. O., Mamone, F., ... Mandraffino, G. (2017). Clinical impact of angiotensin I converting enzyme polymorphisms in subjects with resistant hypertension. Molecular and Cellular Biochemistry, 430, 91-98.

Jartti, L., Raitakari, O. T., Kaprio, J., Jarvisalo, M. J., Toikka, J. O., Marniemi, J., ... Ronnemaa, T. (2002). Increased carotid intima-media thickness in men born in east Finland: A twin study of the effects of birthplace and migration to Sweden on subclinical atherosclerosis. Annals of Medicine, 34, 162-170.

Jartti, L., Ronnemaa, T., Raitakari, O. T., Hedlund, E., Hammar, N., Lassila, R., ... Kaprio, J. (2009). Migration at early age from a high to a lower coronary heart disease risk country lowers the risk of subclinical atherosclerosis in middle-aged men. Journal of Internal Medicine, 265, 345358.

Juo, S. H. (2009). Genetics of carotid atherosclerosis. Frontiers in Bioscience (Landmark edition), 14, 4525-4534.

Juo, S. H., Lin, H. F., Rundek, T., Sabala, E. A., Boden-Albala, B., Park, N., ... Sacco, R. L. (2004). Genetic and environmental contributions to carotid intima-media thickness and obesity phenotypes in the Northern Manhattan Family Study. Stroke, 35, 2243-2247.

Juo, S. H., Rundek, T., Lin, H. F., Cheng, R., Lan, M. Y., Huang, J. S., ... Sacco, R. L. (2005). Heritability of carotid artery distensibility in Hispanics: The Northern Manhattan Family Study. Stroke, 36, 2357-2361.

Kanters, S. D., Algra, A., van Leeuwen, M. S., \& Banga, J. D. (1997). Reproducibility of in vivo carotid intima-media thickness measurements: A review. Stroke, 28, 665-671.

Kao, W. H., Hsueh, W. C., Rainwater, D. L., O’Leary, D. H., Imumorin, I. G., Stern, M. P., \& Mitchell, B. D. (2005). Family history of type 2 diabetes is associated with increased carotid artery intimal-medial thickness in Mexican Americans. Diabetes Care, 28, 1882-1889.

Kerwin, W. S., Hatsukami, T., Yuan, C., \& Zhao, X. Q. (2013). MRI of carotid atherosclerosis. American Journal of Roentgenology, 200, W304-W313.
Kim, D. S., Li, Y. K., Bell, G. A., Burt, A. A., Vaisar, T., Hutchins, P. M., ... Jarvik, G. P. (2016). Concentration of smaller high-density lipoprotein particle (HDL-P) is inversely correlated with carotid intima media thickening after confounder adjustment: The Multi Ethnic Study of Atherosclerosis (MESA). Journal of the American Heart Association, 5, e002977.

Kuipers, A. L., Kammerer, C. M., Miljkovic, I., Woodard, G. A., Bunker, C. H., Patrick, A. L., ... Zmuda, J. M. (2013). Genetic epidemiology and genome-wide linkage analysis of carotid artery ultrasound traits in multigenerational African ancestry families. Atherosclerosis, 231, 120-123.

Kuller, L. H., Shemanski, L., Psaty, B. M., Borhani, N. O., Gardin, J., Haan, M. N., ... Tracy, R. (1995). Subclinical disease as an independent risk factor for cardiovascular disease. Circulation, 92, 720-726.

Kulshreshtha, A., Goyal, A., Veledar, E., McClellan, W., Judd, S., Eufinger, S. C., ... Vaccarino, V. (2014). Association between ideal cardiovascular health and carotid intima-media thickness: A twin study. Journal of the American Heart Association, 3, e000282.

Lange, L. A., Bowden, D. W., Langefeld, C. D., Wagenknecht, L. E., Carr, J. J., Rich, S. S., ... Freedman, B. I. (2002). Heritability of carotid artery intima-medial thickness in type 2 diabetes. Stroke, 33, 1876-1881.

Lassila, R., Seyberth, H. W., Haapanen, A., Schweer, H., Koskenvuo, M., \& Laustiola, K. E. (1988). Vasoactive and atherogenic effects of cigarette smoking: A study of monozygotic twins discordant for smoking. The British Medical Journal, 297, 955-957.

Lee, K., Sung, J., Lee, S. C., Park, S. W., Kim, Y. S., Lee, J. Y., ... Song, Y. M. (2012a). Segment-specific carotid intimamedia thickness and cardiovascular risk factors in Koreans: The Healthy Twin Study. European Journal of Preventive Cardiology, 19, 1161-1172.

Lee, K., Sung, J., Lee, S. C., Park, S. W., Kim, Y. S., Lee, J. Y., \& Song, Y. M. (2012b). Phenotypic and genetic relationships between kidney function and carotid intima-media thickness in Koreans: The Healthy Twin Study. Kidney and Blood Pressure Research, 35, 259-264.

Li, C., Chen, W., Jiang, F., Simino, J., Srinivasan, S. R., Berenson, G. S., \& Mei, H. (2015). Genetic association and gene-smoking interaction study of carotid intima-media thickness at five GWAS-indicated genes: The Bogalusa Heart Study. Gene, 562, 226-231.

Li, C., Jin, X. P., Zhu, M., Chen, Q. L., Wang, F., Hu, X. F., ... Zheng, Z. (2014). Positive association of MMP 14 gene polymorphism with vulnerable carotid plaque formation in a Han Chinese population. Scandinavian Journal of Clinical and Laboratory Investigation, 74, 248-253.

Li, H., Kuipers, A., Kammerer, C. M., Bunker, C. H., Kuller, L. H., Miljkovic, I., ... Zmuda, J. M. (2013). The association between renal function biomarkers and subclinical cardiovascular measures in African Caribbean families. Ethnicity \& Disease, 23, 492-498.

Li, Q., Huang, P., He, Q. C., Lin, Q. Z., Wu, J., \& Yin, R. X. (2014). Association between the CETP polymorphisms and the risk of Alzheimer's disease, carotid atherosclerosis, 
longevity, and the efficacy of statin therapy. Neurobiology of Aging, 35, e1513-e1523.

Li, T. C., Li, C. I., Liao, L. N., Liu, C. S., Yang, C. W., Lin, C. H., ... Lin, C. C. (2015). Associations of EDNRA and EDN1 polymorphisms with carotid intima media thickness through interactions with gender, regular exercise, and obesity in subjects in Taiwan: Taichung Community Health Study (TCHS). Biomedicine (Taipei), 5, 8-14.

Lioudaki, S., Verikokos, C., Kouraklis, G., Ioannou, C., Chatziioannou, E., Perrea, D., \& Klonaris, C. (2017). Paraoxonase-1: Characteristics and role in atherosclerosis and carotid artery disease. Current Vascular Pharmacology, $20,323-334$.

Litvinov, D., Mahini, H., \& Garelnabi, M. (2012). Antioxidant and anti-inflammatory role of paraoxonase 1: Implication in arteriosclerosis diseases. North American Journal of Medicine \& Science, 4, 523-532.

Lopez-Mejias, R., Genre, F., Garcia-Bermudez, M., Ubilla, B., Castaneda, S., Llorca, J., ... Gonzalez-Gay, M. A. (2014). Lack of association between ABO, PPAP2B, ADAMST7, PIK3CG, and EDNRA and carotid intima-media thickness, carotid plaques, and cardiovascular disease in patients with rheumatoid arthritis. Mediators of Inflammation, 2014, 756279 .

Lorenz, M. W., Markus, H. S., Bots, M. L., Rosvall, M., \& Sitzer, M. (2007). Prediction of clinical cardiovascular events with carotid intima-media thickness: A systematic review and meta-analysis. Circulation, 115, 459-467.

Lucatelli, P., Fagnani, C., Tarnoki, A. D., Tarnoki, D. L., Sacconi, B., Fejer, B., ... Medda, E. (2017). Genetic influence on femoral plaque and its relationship with carotid plaque: An international twin study. International Journal of Cardiovascular Imaging, 34, 531-541.

Mackness, B., Durrington, P. N., \& Mackness, M. I. (1998). Human serum paraoxonase. General Pharmacology, 31, 329-336.

Mahdessian, H., Perisic Matic, L., Lengquist, M., Gertow, K., Sennblad, B., Baldassarre, D., ... IMPROVE study group. (2017). Integrative studies implicate matrix metalloproteinase-12 as a culprit gene for large-artery atherosclerotic stroke. Journal of Internal Medicine, 282, 429-444.

Markus, H., Kapozsta, Z., Ditrich, R., Wolfe, C., Ali, N., Powell, J., ... Cullinane, M. (2001). Increased common carotid intima-media thickness in UK African Caribbeans and its relation to chronic inflammation and vascular candidate gene polymorphisms. Stroke, 32, 2465-2471.

Mayosi, B. M., Avery, P. J., Baker, M., Gaukrodger, N., Imrie, H., Green, F. R., ... Keavney, B. (2005). Genotype at the $174 \mathrm{G} / \mathrm{C}$ polymorphism of the interleukin- 6 gene is associated with common carotid artery intimal-medial thickness: Family study and meta-analysis. Stroke, 36, 22152219.

Mazurek, K., Zmijewski, P., Czajkowska, A., \& Lutoslawska, G. (2014). Gender differences in carotid artery intima-media thickness and flow-mediated dilatation in young, physically active adults. Journal of Sports Medicine and Physical Fitness, 54, 298-306.
Medda, E., Fagnani, C., Schillaci, G., Tarnoki, A. D., Tarnoki, D. L., Baracchini, C., ... Stazi, M. A. (2014). Heritability of arterial stiffness and carotid intima-media thickness: An Italian twin study. Nutrition, Metabolism \& Cardiovascular Diseases, 24, 511-517.

Melton, P. E., Carless, M. A., Curran, J. E., Dyer, T. D., Goring, H. H., Kent, J. W., ... Almasy, L. (2013). Genetic architecture of carotid artery intima-media thickness in Mexican Americans. Circulation-Cardiovascular Genetics, 6, 211221.

Millwood, I. Y., Bennett, D. A., Holmes, M. V., Boxall, R., Guo, Y., Bian, Z., ... China Kadoorie Biobank Collaborative, G. (2018). Association of CETP gene variants with risk for vascular and nonvascular diseases among Chinese adults. JAMA Cardiology, 3, 34-43.

Miyaki, K. (2010). Genetic polymorphisms in homocysteine metabolism and response to folate intake: A comprehensive strategy to elucidate useful genetic information. Journal of Epidemiology, 20, 266-270.

Moskau, S., Golla, A., Grothe, C., Boes, M., Pohl, C., \& Klockgether, T. (2005). Heritability of carotid artery atherosclerotic lesions: An ultrasound study in 154 families. Stroke, 36, 5-8.

Naqvi, T. Z., \& Lee, M. S. (2014). Carotid intima-media thickness and plaque in cardiovascular risk assessment. JACC: Cardiovascular Imaging, 7, 1025-1038.

Naqvi, T. Z., Mendoza, F., Rafii, F., Gransar, H., Guerra, M., Lepor, N., ... Shah, P. K. (2010). High prevalence of ultrasound detected carotid atherosclerosis in subjects with low Framingham risk score: Potential implications for screening for subclinical atherosclerosis. Journal of the American Society of Echocardiography, 23, 809-815.

Nikpay, M., Goel, A., Won, H. H., Hall, L. M., Willenborg, C., Kanoni, S., ... Farrall, M. (2015). A comprehensive 1,000 Genomes-based genome-wide association meta-analysis of coronary artery disease. Nature Genetics, 47, 1121-1130.

North, K. E., MacCluer, J. W., Devereux, R. B., Howard, B. V., Welty, T. K., Best, L. G., ... Strong Heart Family Study. (2002). Heritability of carotid artery structure and function: The Strong Heart Family Study. Arteriosclerosis, Thrombosis, and Vascular Biology, 22, 1698-1703.

Park, E. Y., Ahn, H. M., Lee, J. A., \& Hong, Y. M. (2009). Insertion/deletion polymorphism of angiotensin converting enzyme gene in Korean hypertensive adolescents. Heart Vessels, 24, 193-198.

Paternoster, L., Martinez-Gonzalez, N. A., Charleton, R., Chung, M., Lewis, S., \& Sudlow, C. L. (2010). Genetic effects on carotid intima-media thickness: Systematic assessment and meta-analyses of candidate gene polymorphisms studied in more than 5000 subjects. Circulation. Cardiovascular Genetics, 3, 15-21.

Pessi, T., Viiri, L. E., Raitoharju, E., Astola, N., Seppala, I., Waldenberger, M., ... Monaco, C. (2015). Interleukin-6 and microRNA profiles induced by oral bacteria in human atheroma derived and healthy smooth muscle cells. Springerplus, 4, 206.

Phan, T. G., Beare, R. J., Jolley, D., Das, G., Ren, M., Wong, K., ... Srikanth, V. (2012). Carotid artery anatomy and 
geometry as risk factors for carotid atherosclerotic disease. Stroke, 43, 1596-1601.

Pignoli, P., Tremoli, E., Poli, A., Oreste, P., \& Paoletti, R. (1986). Intimal plus medial thickness of the arterial wall: A direct measurement with ultrasound imaging. Circulation, 74, 1399-1406.

Pleskovic, A., Letonja, M. S., Vujkovac, A. C., Starcevic, J. N., Caprnda, M., Curilla, E., ... Petrovic, D. (2017). Matrix metalloproteinase-3 gene polymorphism (rs3025058) affects markers atherosclerosis in type 2 diabetes mellitus. Vasa, 46, 363-369.

Polak, J. F., Pencina, M. J., Pencina, K. M., O’Donnell, C. J., Wolf, P. A., \& D'Agostino, R. B. (2011). Carotid-wall intima-media thickness and cardiovascular events. The New England Journal of Medicine, 365, 213-221.

Polak, J. F., Person, S. D., Wei, G. S., Godreau, A., Jacobs, D. R., Harrington, A., ... O'Leary, D. H. (2010). Segment-specific associations of carotid intima-media thickness with cardiovascular risk factors: The Coronary Artery Risk Development in Young Adults (CARDIA) Study. Stroke, 41, 915.

Pott, J., Burkhardt, R., Beutner, F., Horn, K., Teren, A., Kirsten, H., .. Scholz, M. (2017). Genome-wide meta-analysis identifies novel loci of plaque burden in carotid artery. Atherosclerosis, 259, 32-40.

Pramukarso, D. T., Faradz, S. M., Sari, S., \& Hadisaputro, S. (2015). Association between methylenetetrahydrofolate reductase (MTHFR) polymorphism and carotid intima medial thickness progression in post ischaemic stroke patient. Annals of Translational Medicine, 3, 324.

Proust, C., Empana, J. P., Boutouyrie, P., Alivon, M., Challande, P., Danchin, N., ... Lacolley, P. (2015). Contribution of rare and common genetic variants to plasma lipid levels and carotid stiffness and geometry: A substudy of the Paris Prospective Study 3. Circulation Cardiovascular Genetics, 8, 628-636.

Rampersaud, E., Bielak, L. F., Parsa, A., Shen, H., Post, W., Ryan, K. A., ... Mitchell, B. D. (2008). The association of coronary artery calcification and carotid artery intimamedia thickness with distinct, traditional coronary artery disease risk factors in asymptomatic adults. American Journal of Epidemiology, 168, 1016-1023.

Rauramaa, R., Vaisanen, S. B., Luong, L. A., SchmidtTrucksass, A., Penttila, I. M., Bouchard, C., ... Humphries, S. E. (2000). Stromelysin-1 and interleukin-6 gene promoter polymorphisms are determinants of asymptomatic carotid artery atherosclerosis. Arteriosclerosis, Thrombosis, and Vascular Biology, 20, 2657-2662.

Riikola, A., Sipila, K., Kahonen, M., Jula, A., Nieminen, M. S., Moilanen, L., ... Hulkkonen, J. (2009). Interleukin-6 promoter polymorphism and cardiovascular risk factors: The Health 2000 Survey. Atherosclerosis, 207, 466-470.

Rundek, T., Elkind, M.S., Pittman, J., Boden-Albala, B., Martin, S., Humphries, S. E., ... Sacco, R. L. (2002). Carotid intima-media thickness is associated with allelic variants of stromelysin-1, interleukin-6, and hepatic lipase genes: The Northern Manhattan Prospective Cohort Study. Stroke, 33, $1420-1423$.
Ryabikov, A., Malyutina, S., Ryabikov, M., Kuznetsova, T., Staessen, J. A., \& Nikitin, Y. (2007). Intrafamilial correlations of carotid intima-media thickness and flow-mediated dilation in a Siberian population. American Journal of $\mathrm{Hy}$ pertension, 20, 248-254.

Ryder, J. R., Pankratz, N. D., Dengel, D. R., Pankow, J. S., Jacobs, D. R., Sinaiko, A. R., ... Steinberger, J. (2017). Heritability of vascular structure and function: A ParentChild Study. Journal of the American Heart Association, 6, e004757.

Sacco, R. L., Blanton, S. H., Slifer, S., Beecham, A., Glover, K., Gardener, H., ... Rundek, T. (2009). Heritability and linkage analysis for carotid intima-media thickness: The family study of stroke risk and carotid atherosclerosis. Stroke, 40, 2307-2312.

Salonen, J. T., \& Salonen, R. (1991). Ultrasonographically assessed carotid morphology and the risk of coronary heart disease. Arteriosclerosis and Thrombosis, 11, 1245-1249.

Sayed-Tabatabaei, F. A., Houwing-Duistermaat, J. J., van Duijn, C. M., \& Witteman, J. C. (2003). Angiotensinconverting enzyme gene polymorphism and carotid artery wall thickness: A meta-analysis. Stroke, 34, 1634-1639.

Sayed-Tabatabaei, F. A., van Rijn, M. J., Schut, A. F., Aulchenko, Y. S., Croes, E. A., Zillikens, M. C., ... van Duijn, C. M. (2005). Heritability of the function and structure of the arterial wall: Findings of the Erasmus Rucphen Family (ERF) Study. Stroke, 36, 2351-2356.

Shendre, A., Irvin, M. R., Aouizerat, B. E., Wiener, H. W., Vazquez, A. I., Anastos, K., ... Shrestha, S. (2014). RYR3 gene variants in subclinical atherosclerosis among HIVinfected women in the Women's Interagency HIV Study (WIHS). Atherosclerosis, 233, 666-672.

Shendre, A., Wiener, H. W., Irvin, M. R., Aouizerat, B. E., Overton, E. T., Lazar, J., ... Shrestha, S. (2017). Genomewide admixture and association study of subclinical atherosclerosis in the Women's Interagency HIV Study (WIHS). PLoS One, 12, e0188725.

Shrestha, S., Irvin, M. R., Taylor, K. D., Wiener, H. W., Pajewski, N. M., Haritunians, T., ... Grunfeld, C. (2010). A genome-wide association study of carotid atherosclerosis in HIV-infected men. Journal of Acquired Immune Deficiency Syndromes, 24, 583-592.

Singh, A., Babyak, M. A., Nolan, D. K., Brummett, B. H., Jiang, R., Siegler, I. C., ... Hauser, E. R. (2015). Gene by stress genome-wide interaction analysis and path analysis identify EBF1 as a cardiovascular and metabolic risk gene. European Journal of Human Genetics, 23, 854-862.

Song, Y. M., Lee, K., Sung, J., Kim, Y. S., \& Lee, J. Y. (2012). Sexspecific relationships between adiposity and anthropometric measures and carotid intima-media thickness in Koreans: The Healthy Twin Study. European Journal of Clinical Nutrition, 66, 39-46.

Stein, J. H., Korcarz, C. E., Hurst, R. T., Lonn, E., Kendall, C. B., Mohler, E. R., ... American Society of Echocardiography Carotid Intima-Media Thickness Task, F. (2008). Use of carotid ultrasound to identify subclinical vascular disease and evaluate cardiovascular disease risk: A consensus statement from the American society of echocardiography 
carotid intima-media thickness task force. endorsed by the society for vascular medicine. Journal of the American Society of Echocardiography, 21, 93-111, quiz 189-190.

Sun, K., Song, J., Liu, K., Fang, K., Wang, L., Wang, X., ... Hu, Y. (2017). Associations between homocysteine metabolism related SNPs and carotid intima-media thickness: A Chinese sib pair study. Journal of Thrombosis and Thrombolysis, 43, 401-410.

Susser, M., \& Susser, E. (1987). Indicators and designs in genetic epidemiology: Separating heredity and environment. Revue d'Epidémiologie et de Santé Publique, 35, 54-77.

Swan, L., Birnie, D. H., Inglis, G., Connell, J. M., \& Hillis, W. S. (2003). The determination of carotid intima medial thickness in adults - A population-based twin study. Atherosclerosis, 166, 137-141.

Tarnoki, A. D., Baracchini, C., Tarnoki, D. L., Lucatelli, P., Boatta, E., Zini, C., ... Schillaci, G. (2012). Evidence for a strong genetic influence on carotid plaque characteristics: An international twin study. Stroke, 43, 3168-3172.

Tsai, M. Y., Johnson, C., Kao, W. H., Sharrett, A. R., Arends, V. L., Kronmal, R., ... Post, W. (2008). Cholesteryl ester transfer protein genetic polymorphisms, HDL cholesterol, and subclinical cardiovascular disease in the multi-ethnic study of atherosclerosis. Atherosclerosis, 200, 359-367.

van der Meer, I. M., Bots, M. L., Hofman, A., del Sol, A. I., van der Kuip, D. A., \& Witteman, J. C. (2004). Predictive value of noninvasive measures of atherosclerosis for incident myocardial infarction: The Rotterdam Study. Circulation, 109, 1089-1094.

Vargas, J. D., Manichaikul, A., Wang, X. Q., Rich, S. S., Rotter, J. I., Post, W. S., ... Bluemke, D. A. (2016). Common genetic variants and subclinical atherosclerosis: The multi-ethnic study of atherosclerosis (MESA). Atherosclerosis, 245, 230236.

Wang, D., Yang, H., Quinones, M. J., Bulnes-Enriquez, I., Jimenez, X., De La Rosa, R., ... Rotter, J. I. (2005). A genome-wide scan for carotid artery intima-media thickness: The Mexican-American coronary artery disease family study. Stroke, 36, 540-545.

Wang, F., Jin, X. P., Zhu, M., Lin, X. F., Hu, X. F., Wang, W. F., ... Huang, L. Z. (2011). Genotype association of C(-735)T polymorphism of the MMP-2 gene with the risk of carotid atherosclerosis-vulnerable plaque in the Han Chinese population. Vascular Medicine, 16, 13-18.

Wasserman, B. A., Astor, B. C., Sharrett, A. R., Swingen, C., \& Catellier, D. (2010). MRI measurements of carotid plaque in the Atherosclerosis Risk in Communities (ARIC) Study: Methods, reliability and descriptive statistics. Journal of Magnetic Resonance Imaging, 31, 406-415.

Whincup, P. H., Nightingale, C. M., Owen, C. G., Rapala, A., Bhowruth, D. J., Prescott, M. H., ... Deanfield, J. E. (2012). Ethnic differences in carotid intima-media thickness between UK children of black African-Caribbean and white European origin. Stroke, 43, 1747-1754.

Wikstrand, J. (2007). Methodological considerations of ultrasound measurement of carotid artery intima-media thick- ness and lumen diameter. Clinical Physiology and Functional Imaging, 27, 341-345.

Wilkening, S., Chen, B., Bermejo, J. L., \& Canzian, F. (2009). Is there still a need for candidate gene approaches in the era of genome-wide association studies? Genomics, 93, 415-419.

Woessner, J. F. (1991). Matrix metalloproteinases and their inhibitors in connective-tissue remodeling. FASEB Journal, 5, 2145-2154.

Wong, M., Edelstein, J., Wollman, J., \& Bond, M. G. (1993). Ultrasonic-pathological comparison of the human arterial wall. Verification of intima-media thickness. Arteriosclerosis, Thrombosis, and Vascular Biology, 13, 482-486.

World Health Organization. (2017). Cardiovascular disease. Retrieved from http://www.who.int/cardiovascular_ diseases/en/

Xiang, A. H., Azen, S. P., Buchanan, T. A., Raffel, L. J., Tan, S., Cheng, L. S., ... Hodis, H. N. (2002). Heritability of subclinical atherosclerosis in Latino families ascertained through a hypertensive parent. Arteriosclerosis, Thrombosis, and Vascular Biology, 22, 843-848.

Xie, G., Myint, P. K., Voora, D., Laskowitz, D. T., Shi, P., Ren, F., ... Wu, Y. (2015). Genome-wide association study on progression of carotid artery intima media thickness over 10 years in a Chinese cohort. Atherosclerosis, 243, 30-37.

Yang, J., Lee, S. H., Goddard, M. E., \& Visscher, P. M. (2011). GCTA: A tool for genome-wide complex trait analysis. American Journal of Human Genetics, 88, 76-82.

Ye, S., Eriksson, P., Hamsten, A., Kurkinen, M., Humphries, S. E., \& Henney, A. M. (1996). Progression of coronary atherosclerosis is associated with a common genetic variant of the human stromelysin-1 promoter which results in reduced gene expression. Journal of Biological Chemistry, 271, 13055-13060.

Yu, G. I., Jun, S. E., Cho, H. C., Park, K. O., Chung, J. H., Shin, D. H., \& Chung, I. S. (2015). Association of interleukin10 promoter region polymorphisms with risk factors of Atherosclerosis. International Journal of Immunogenetics, 42, 31-37.

Zhang, Y., Wang, L., Zhang, Z., Zhang, Z., Zhou, S., Cao, L., ... Xu, G. (2015). Shared and discrepant susceptibility for carotid artery and aortic arch calcification: A genetic association study. Atherosclerosis, 241, 371-375.

Zhao, C., Ikeda, S., Arai, T., Naka-Mieno, M., Sato, N., Muramatsu, M., \& Sawabe, M. (2014). Association of the RYR3 gene polymorphisms with atherosclerosis in elderly Japanese population. BMC Cardiovascular Disorders, 14, 6.

Zhao, J., Cheema, F. A., Bremner, J. D., Goldberg, J., Su, S., Snieder, H., ... Vaccarino, V. (2008). Heritability of carotid intima-media thickness: A twin study. Atherosclerosis, 197, 814-820.

Zhi, D., Shendre, A., Scherzer, R., Irvin, M. R., Perry, R. T., Levy, S., ... Shrestha, S. (2015). Deep sequencing of RYR3 gene identifies rare and common variants associated with increased carotid intima-media thickness (CIMT) in HIVinfected individuals. Journal of Human Genetics, 60, 63-67. 